\title{
Crimes, vítimas e policiais
}

\author{
ANTÔNIO LUIZ PAIXÃO
}

(in memorian)

\author{
CLAUDIO C. BEATO F.
}

\begin{abstract}
RESUMO: Com base nos dados de vitimização levantados pela PNAD 88, os autores analisam as relações entre polícia e sociedade, através de discussão dos motivos que levam as pessoas a procurarem ou não a polícia. Em contraposição a uma explicação de natureza "culturalista", é sugerida a hipótese de que existem motivações racionais para se acionar a polícia para a resolução de conflitos.
\end{abstract}

\section{Introdução}

transição democrática brasileira encontra incômoda companhia no crescimento das taxas de criminalidade violenta nas áreas metropolitanas brasileiras desde os anos 1970 (Coelho, 1988) alterando substancialmente o diagnóstico e as terapias recomendadas de resolução de problema central da construção da ordem democrática - 0 controle coercitivo, pela autoridade pública, de comportamentos individuais e coletivos desviantes em relação às regras legais. Apenas recentemente a sociedade brasileira se apercebeu das articulações positivas entre polícia e cidadania. A longa tradição (e experiência) de uma polícia de gente, dócil em relação aos privilégios de classe e status em sua atividade rotineira de imposição da ordem, e de uma a polícia de moleque, nunca hesitante em usar o chicote no trabalho de domesticação das rebeldias individuais e coletivas das classes baixas traduziu o problema do controle social coercitivo nos termos de alguma redução do poder da polícia no Brasil, como condição de construção da democracia no plano das interações sociais rotineiras e cotidianas (Paixão, 1988). A violência instrumental da polícia de moleque afetava a garantia dos
UNITERMOS: criminalidade, violência, vitimização, polícia, polícia/sociedade, motivações, resolução de conflitos.

Professores do Departamento de Sociologia e Antropologia da UFMG 
direitos civis tanto como negação das formalidades que definem o due process of law quanto por sua incapacidade de conter efetivamente a escalada criminosa. Não resultava dela a punição justa, rápida e certeira da predação criminosa - certamente ingrediente central da estratégia democrática de redução das taxas de criminalidade.

Assim, o problema do controle social - do ponto de vista da consolidação da democracia no Brasil - envolve, a um só tempo, contenção e efetividade. Por um lado, trata-se de conter não só o arbítrio da polícia de moleque mas também o particularismo da polícia de gente - uma e outra conspiram, igualmente, contra a realização dos direitos civis que define o controle social democrático. Por outro lado, este se torna ficção quando a ação da polícia e do judiciário não afeta o comportamento das taxas de criminalidade, como indicam algumas observações empíricas (cf. Coelho, 1988): em São Paulo, entre 1981 e 1984 a polícia sequer investigou 89\% das ocorrências de roubo; $81 \%$ das ocorrências de estupro e $29 \%$ dos casos de homicídio (em contraste com a média americana de 12\%). Os tribunais liberaram, entre 1976 e $1984,54 \%$ dos denunciados por homicídio, $74 \%$ dos denunciados por estupro e $47 \%$ dos denunciados por roubo. Dos condenados saídos da prisão em 1982 , apenas $12 \%$ haviam cumprido suas penas e $55 \%$ foram beneficiados por sursis.

A crítica humanitária aos métodos violentos de trabalho da polícia não pode negligenciar os efeitos devastadores - do ponto de vista dos direitos humanos - da baixa efetividade das organizações do sistema de justiça criminal no combate à criminalidade: um deles é o estímulo a resoluções extralegais de agressões criminosas; outro é a facilitação de cruzadas morais de forte conteúdo autoritário - de um e de outro resultam, no plano da psicologia social, o reforço de atitudes de cinismo e descrença frente à competência de modelos democráticos de resolução de conflitos.

Pouco (se tanto) conhecemos sobre os efeitos desse sistema policial e judiciário sobre a sociedade. As taxas espetaculares de criminalidade violenta e de crimes hediondos não investigados pela polícia no Brasil, bem como a magnitude de ocorrências criminosas não comunicadas pelas vítimas à polícia (cf. Coelho, 1988; IBGE, 1990) não têm sido sistematicamente analisadas. Neste trabalho, analisaremos as reações de vítimas de crime, suas razões e motivos para comunicar ou não comunicar à polícia os eventos criminais em que se envolveram, através do exame dos dados de survey sobre vitimização criminal produzido pelo IBGE (1990). O estudo das reações das vítimas de crime são indicadores importantes de medida do grau de confiança das populações em relação ao trabalho institucional da polícia. Encontramos no trabalho clássico de Almond e Verba (1965) atitudes em relação à polícia como variável estratégica na identificação de variações entre contextos nacionais e temporais no suporte e adesão populares à democracia política. Em outras palavras, este artigo procura explorar as conexões entre comportamento e atitudes de populações afetadas diretamente pelo crime e suas 
avaliações da polícia, certamente ingrediente central dos requisitos psicossociais - na forma de introjeção de uma "cultura cívica" pelo corpo de cidadãos - da consolidação democrática. Na próxima seção, discutiremos as relações tensas e complexas entre polícia e democracia. Após a análise dos dados discutiremos algumas complexidades por ela suscitados. Uma delas tem a ver com avaliações pessimistas quanto à capacidade das elites políticas brasileiras na construção do "Estado mínimo" nos termos definidos pelo pensamento liberal, aptamente elaborada por W. Guilherme dos Santos (cf. 1993). Outra tem a ver com algumas especulações sobre a natureza cambiante das instituições de controle social em sociedades altamente diferenciadas e socialmente pluralistas.

\section{Polícia e democracia: ordem sob a lei}

O idioma político das sociedades modernas encontrou no ideal de "ordem sob a lei" a resolução do problema representado pelo uso instrumental da violência nas interações sociais. Ao concentrar no Estado e em suas instituições de controle social o monopólio do uso legítimo dos meios de violência, a ordem jurídica "expropria" dos indivíduos o recurso à violência como meio de atingir fins e realizar o elemento central da noção de cidadania: a proteção pública e estatal dos cidadãos contra os custos externos correspondentes à ameaça criminosa. Assim, a polícia implementa, em cada esquina, a função essencial do Estado: a imposição coercitiva das regras de regulação de comportamentos que garantem o sono tranqüilo do proprietário de Adam Smith e reduzem o risco da morte violenta que atemorizava Thomas Hobbes.

O uso instrumental dos meios de violência pelo policial na produção de ordem define o papel da polícia: nas questões internas do Estado, a violência funciona como último recurso de contenção dos "indivíduos isolados... que se recusam a ser dominados pelo consenso da maioria" (Arendt, 1985, p. 27). A restrição legal ao arbítrio policial no uso de violência representa segundo elemento crucial da noção de cidadania: a proteção dos direitos e liberdades civis potencialmente ameaçados pela coerção das organizações do Estado (cf. Offe, 1987). O modelo de "ordem sob a lei”" encontra na subordinação da polícia ao judiciário e na conformidade compulsória do trabalho policial às regras do due process as condições que fazem da atividade policial a garantia da liberdade humana. A vigência efetiva dessas condições distingue o estado democrático do estado autoritário, também conhecido como Estado policial em razão dos graus elevados de liberdade das agências de repressão.

O modelo de "ordem sob a lei" descreve dupla domesticação. Por um lado, o controle social coercitivo de minorias desobedientes indica a natureza punitiva da ordem social democrática - a contrapartida da generalização das liberdades é a intolerância punitiva em relação a comportamentos que escapam das normas da lei e da ordem que incorporam a vontade soberana da 
maioria. Nesse sentido, o problema da polícia na ordem social democrática é garantir o consenso moral - seja fazendo o crime não compensar pela detenção rápida e certeira do criminoso, seja comunicando à periferia social as regras públicas de comportamento da sociedade democrática -, a proscrição do ócio, do vício, do crime e da violência instrumental. Por outro lado, a polícia é objeto a ser contido, dado o potencial de ameaça ao pleno exercício, pelo cidadão, de suas liberdades negativas, representado pelo uso arbitrário de poder pelos agentes do estado no combate ao crime. O primeiro problema é de eficácia na provisão de ordem, justiça e paz e envolve concentração de poder simbólico e instrumental na organização policial; o segundo problema envolve restrição no uso de poder pelo policial na produção de ordem. Ou seja, o modelo de "ordem sob a lei" envolve paradoxo argutamente identificado pela análise organizacional: "ordem" significa conformidade a padrões absolutos de moralidade enquanto "lei”" representa limites racionais à imposição de ordem. Logo, é possível postular a incompatibilidade potencial entre justiça substantiva e justiça formal, retoricamente articuladas no modelo (cf. Skolnick, 1966).

A criação da moderna polícia burocrática se impôs tanto como barreira pública ao confronto direto de classes quanto como o meio tecnicamente mais eficiente de provisão de justiça e paz na sociedade industrial. F. Engels não percebeu adequadamente o problema: ao notar que a burguesia "precisava do Estado para manter em ordem os trabalhadores (mas) fazia de tudo para impedir a intervenção do Estado em seus próprios negócios" (Engels, 1968, p. 313), ele negligenciava a teoria liberal emergente do estado como agente regulador de externalidades geradas nas interações sociais. Em outras palavras, a invenção da moderna polícia burocrática dotou o Estado de um instrumento de implementação de políticas públicas de segurança: "burocracias públicas não haviam eliminado as pragas, solucionado o velho problema sanitário urbano e impedido poluições grosseiras nos alimentos? Por que, similarmente, a polícia não solucionaria o crime e controlaria a violência?" (cf. Silver, 1967, p. 21).

A discussão anterior permite descrever o dilema do trabalho policial na sociedade democrática: como maximizar a implementação da lei entre indivíduos potencialmente recalcitrantes através da utilização de recursos profissionais. Já nos referimos ao dilema do controle (ou como transformar a polícia em instrumento politicamente neutro de controle social). Um outro dilema tem a ver com o tema das "classes perigosas" como alvo preferencial da ação policial - e este tema permite uma avaliação mais realista do modelo de ordem sob a lei. A pesquisa etnográfica descobriu a natureza complexa da legalidade como parâmetro de orientação, accountability e controle do trabalho policial de patrulha e combate ao crime. A "lógica-em-uso" do policial obedece a outro parâmetro: as regras e preceitos do trabalho policial, codificados no estoque de conhecimento da instituição e comunicados no ofício cotidiano e na sociabilidade dos quartéis e delegacias. Brutalidade, fraude e corrupção podem ser, no contexto apropriado, recursos de investigação ou de 
defesa da sociedade contra agressores notórios, mas maliciosos. Certamente, os graus de liberdade na mobilização de meios eficientes pelo policial varia em função da natureza do regime político. Violência e fraude serão usadas de forma mais desinibida pela polícia de governos autoritários - onde não vigoram as liberdades, direitos, autonomias institucionais e garantias constitucionais das democracias. Mas estas também experimentam, ainda que em menor escala, a natureza problemática do controle do trabalho policial.

A análise sociológica da polícia nas democracias consolidadas (cf. Bittner,1975; Manning,1977; Monet, 1985) mostra que reside no ambiente da organização os determinantes mais significativos de controle da propensão policial ao uso da violência e de restrição aos impulsos no sentido de implementação de modelo "fundamentalista" de ordem na sociedade. A autonomia das instituições legais e sua capacidade efetiva de afetar processos e comportamentos organizacionais e individuais tem peso historicamente significativo na garantia dos direitos de cidadania nas operações das agências públicas de controle social. As decisões da Suprema Corte americana proclamando a precedência dos procedimentos formais face aos resultados substantivos na produção de justiça (os célebres casos Mapp, Escobedo e Miranda) representaram estímulo importante na contenção do uso arbitrário de poder no trabalho investigatório da polícia. As evidências são ambíguas, mas E. Bittner salienta o efeito evolucionário de restrições e controles sobre o comportamento policial: "cada geração de policiais parece aceitar como justas e práticas aquelas restrições legais que a geração anterior tachava de inconvenientes e destrutivas para a eficácia da polícia" (Bittner, 1975).

Um segundo determinante ambiental do controle da polícia é a força e a capacidade de ação efetiva de movimentos sociais de defesa dos direitos civis (cf. Paixão, 1988). A ilustração modelar é o caso dos negros americanos. Os ritos nos guetos negros em 1968 foram a culminação da militância combinada de diferentes organizações de defesa dos direitos civis desde os anos 1950 - e encontramos em rigoroso esforço de análise do comportamento dos coeficientes de correlação entre classe social e criminalidade no período 1941-1977 medida adequada dos efeitos da ação coletiva sobre a polícia. O declínio historicamente observado da magnitude dos coeficientes de correlação (e a virtual independência estatística das duas variáveis desde os anos 1970) encontra explicação plausível nos efeitos conjuntos de decisões da Suprema Corte e da ação dos movimentos sociais sobre as práticas policiais: "no passado, a polícia podia, sem dúvida, exercer vigilância mais cerrada sobre as pessoas de status mais baixo e efetuar prisões baseadas em evidências mais fluidas do que agora ela pode" (Tittle et alii, 1978, p. 652).

A constituição de 1988 representa esforço notável no sentido de regulamentar, com nitidez, os dois elementos da noção de cidadania que descrevemos anteriormente: a proteção dos direitos e liberdades individuais frente às ameaças a eles representadas pela força e poder das instituições do Estado (o âmbito do controle do uso dos meios de violência na produção 
policial de ordem) e a proteção da vida e da propriedade dos cidadãos ameaçadas pela predação criminosa (o âmbito da eficiência no controle social).

\section{A ordem apesar da lei: quem recorre à polícia e porque}

A referência aos componentes ambientais de controle da polícia nos remete ao tema da articulação da organização com as demandas da sociedade por eficiência na ação repressiva. Tais demandas circunscrevem claramente a ação policial em relação aos limites de sua atuação, que não são, como vimos, necessariamente em conformidade às regras de ordem legal. Em determinados contextos, as pessoas podem não recorrer à lei e à polícia para a manutenção da ordem. Existem mecanismos à margem das normas jurídicas e penais através dos quais as pessoas estabelecem uma base de convivência social que não se refere ao governo ou ao Estado e seus agentes. Trata-se da delimitação entre as dimensões pública e privada como um componente ambiental relacionado ao controle e eficiência da ação policial.

Uma indicação desses elementos pode ser encontrada nas questões da PNAD de 1988 sobre vitimização (IBGE, 1990). Algumas se referiam aos motivos pelos quais as pessoas não recorreram à polícia em casos de roubo $\mathrm{e}$ furto e agressão, cujos resultados podemos ver na tabela 1 adiante ${ }^{1}$ :

Trataremos aqui dos dados referentes exclusivamente ao estado de Minas Gerais, pois numa análise preliminar não foi identificado nenhuma variação significativa em relação aos dados referentes ao país. Se compararmos diferentes estados como Rio ou São Paulo, certamente encontraremos diferenças importantes. Mas, neste momento, estes dados não estão à nossa disposição.

\begin{tabular}{|c|c|c|c|c|c|c|c|c|}
\hline \multicolumn{9}{|c|}{ Motivos pelos quais as vítimas de furtos e agressão não recorreram a polícia } \\
\hline & Total & $\begin{array}{c}\text { falta } \\
\text { de provas }\end{array}$ & $\begin{array}{c}\text { não era } \\
\text { importante }\end{array}$ & $\begin{array}{c}\text { não acreditavam } \\
\text { na polícia }\end{array}$ & $\begin{array}{c}\text { não queriam } \\
\text { envolver a polícia }\end{array}$ & $\begin{array}{l}\text { medo de } \\
\text { represália }\end{array}$ & $\begin{array}{r}\text { recorreram } \\
\text { a terceiros }\end{array}$ & $\begin{array}{c}\text { resolveram } \\
\text { sozinhos }\end{array}$ \\
\hline \multirow{2}{*}{ 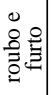 } & 320.786 & 77.596 & 83.393 & 73.105 & 37.101 & 9.796 & 11.956 & 27.839 \\
\hline & $100 \%$ & $24 \%$ & $26 \%$ & $23 \%$ & $12 \%$ & $3 \%$ & $4 \%$ & $9 \%$ \\
\hline \multirow{2}{*}{ 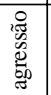 } & 85.984 & 2.696 & 24.147 & 8.854 & 16.526 & 8.910 & 6.215 & 18.636 \\
\hline & $100 \%$ & $3 \%$ & $28 \%$ & $10 \%$ & $19 \%$ & $10 \%$ & $7 \%$ & $22 \%$ \\
\hline
\end{tabular}

Tal como observa-se em outros países, a maioria das vítimas de furtos e roubos encontram-se em idade madura (46\% entre 30 e 50 anos de idade e $26 \%$ entre 18 e 30 anos) e são provenientes de meios urbanos (89\%). O perfil das vítimas de agressão é bastante similar ao das vítimas de furtos e roubos: tratam-se de pessoas que vivem em meios urbanos $(85 \%)$, porém com idade mais jovem, $31 \%$ têm entre 30 e 50 anos de idade e $60 \%$ com menos de 30 anos de idade. 
(\%)

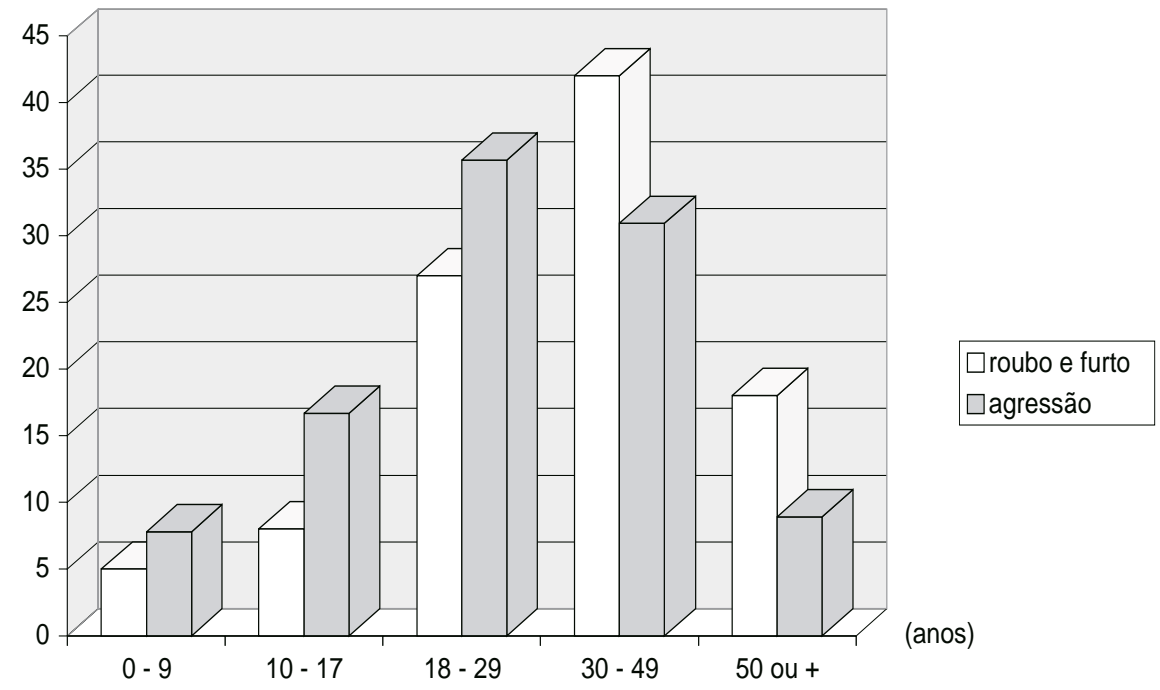

Como as vítimas "absorveram" a experiência? No caso de roubos e furtos, elas não procuraram a polícia por falta de provas $(24 \%)$ ou porque julgavam que não era importante a presença da polícia (26\%). Os motivos alegados pelas vítimas nos sugerem que elas conheciam os autores dos delitos, e houve alguma ponderação a respeito dos constrangimentos que o envolvimento da polícia poderia acarretar. Outro tipo de avaliação a ser considerada pelas vítimas é de ordem material: elas tendem a recorrer tanto mais à polícia quanto maior o valor do objeto roubado ou furtado. Isso ocorre principalmente quando se trata de carros (66\%), motos e outros veículos (43\%) e eletromésticos $(58 \%)$. Isto parece traduzir a percepção de que, somente após uma avaliação custo/benefício que leve em consideração o valor dos objetos roubados, uma identificação bastante clara dos autores, além dos transtornos causados pelo envolvimento policial nesses casos, as vítimas acionarão ou não o estado.

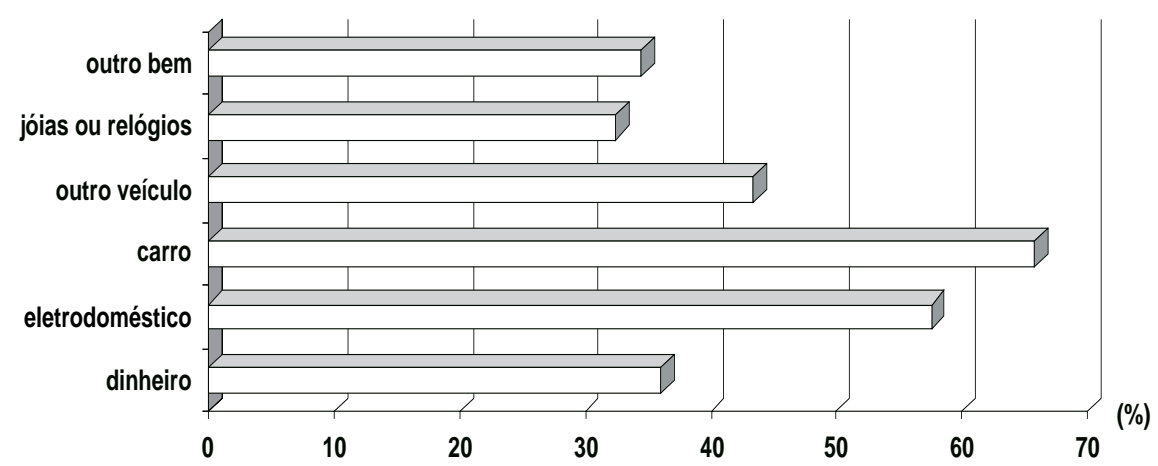

3. Percentual dos que recorreram à polícia por tipo de bem roubado - $M G$.

Uma parcela importante, entretanto, preferiu não envolver a polícia simplesmente porque julgou que não era necessário (12\%). Essa decisão não é uma questão de ordem legal, mas envolve elementos de ordem contextual de avaliação de distintas dimensões normativas tomadas em consideração. Não 
${ }^{2}$ Os dados publicados pela PNAD não nos permitem uma afirmação mais conclusiva a respeito do quanto a freqüência de roubos e furtos ou de agressões - o número de vezes em que as vítimas são assaltadas ou agredidas novamente - levam as pessoas a acionarem ou não a polícia. Mas nos parece que esta é uma hipótese plausível.

3 Dada a natureza de nossas indagações a respeito dos motivos pelos quais as pessoas não procuram a polícia, iremos tomar apenas as vítimas de agressões de parentes e pessoas conhecidas, que constituem $67 \%$ do total das pessoas que não recorreram à polícia $(25 \%$ das ocorrências referem-se a parentes envolvidos e $42 \%$ são de pessoas conhecidas). se trata propriamente de desconfiança em relação à atuação policial, mas de uma avaliação da conveniência dessa atuação: nem todos os conflitos requerem a atuação da força policial, pois podem ser resolvidos privadamente. Certamente uma boa parcela dos que resolveram sozinhos (9\%) ou recorreram a terceiros (4\%) está na intersecção com esta categoria. A desconfiança em relação à polícia, aliás, está representada pelo contingente considerável de $23 \%$ de vítimas que declararam não acreditar nela.

Os dados a respeito de roubos parecem sugerir que o envolvimento da polícia foi ponderado como algo que envolve um custo, tanto do objeto subtraído como aqueles resultantes envolvimento da própria polícia, e tendo em vista uma necessidade, que pode ser traduzido como o grau em que conflitos podem ser resolvidos no âmbito social mais próximo, além da freqüiência com que ocorre o delito ${ }^{2}$.

No caso das agressões, a falta de provas não é decisiva (3\%) para se recorrer ou não à polícia, e o motivo bastante óbvio é o de que o autor é conhecido. É interessante, entretanto, analisarmos mais de perto as categorias de vítimas que não recorreram por não querer envolver a polícia (12\% dentre as vítimas de furto ou roubo e $19 \%$ das vítimas de agressão) ou por não acreditar nela ( $23 \%$ de roubo e furto e $10 \%$ das agressões).

Não ter provas suficientes que justifiquem o envolvimento da polícia pode traduzir muitos sentimentos e motivações: pode tratar-se de uma simples desconfiança cujas conseqüências eventualmente poderiam ter como uma das alternativas possíveis o acionamento da polícia, até evidências comprometedoras, embora insuficientes legalmente. Os resultados são bastante consistentes com a interpretação de que as decisões de se chamar a polícia são contextualmente racionais: conforme podemos ver, a iniciativa de não se recorrer à polícia é bastante comum em vítimas de agressão física (61\% contra 39\% que recorreram). Aparentemente as pessoas resolveram seus conflitos no âmbito privado, especialmente quando se tratava de parentes $(67 \%$ preferem não acionar a polícia), ou pessoas conhecidas (59\%). Por razões diversas, também preferem não acionar a polícia 59\% das vítimas de agressão policial, bem como as vítimas de desconhecidos (58\%). Em relação aos policiais, certamente um contingente considerável não o faz por temor das conseqüências.

Mas será possível delinearmos um padrão dos motivos dessa não recorrência à ação da polícia? Alguma base de inferência é possível após uma análise mais atenta dos dados ${ }^{3}$ dos relacionamentos das vítimas. Já se disse que a sociedade brasileira é avessa ao conflito institucionalmente canalizado, ao qual podemos acrescentar o elevado grau de violência doméstica adiante expresso. Conflitos privados e familiares dificilmente chegam ao conhecimento da polícia: $67 \%$ das pessoas que foram agredidas por parentes ou pessoas conhecida preferem não recorrer à polícia e, quando o fazem, nem sempre chegam a registrar queixas. Conforme vemos no gráfico 4 a seguir, conflitos circunscritos ao âmbito doméstico traduzem uma pauta cultural que dissocia 
PAIXÃO, Antônio Luiz \& BEATO F., Claudio C. Crimes, vítimas e policiais. Tempo Social; Rev. Sociol. USP, S. Paulo, 9(1): 233248, maio de 1997.

o âmbito das relações privadas das instituições públicas. Daí que agressões não sejam tratadas como questões de polícia. $66 \%$ dos autores são parentes e pessoas conhecidas em conflitos que ocorrem no âmbito doméstico e da vizinhança. A questão, portanto, não é a inexistência de conflitos, mas a idéia de que eles são estritamente privados e sua resolução ampara-se, talvez, no conhecido provérbio de que "roupa suja lava-se em casa".

\section{$(\%)$}

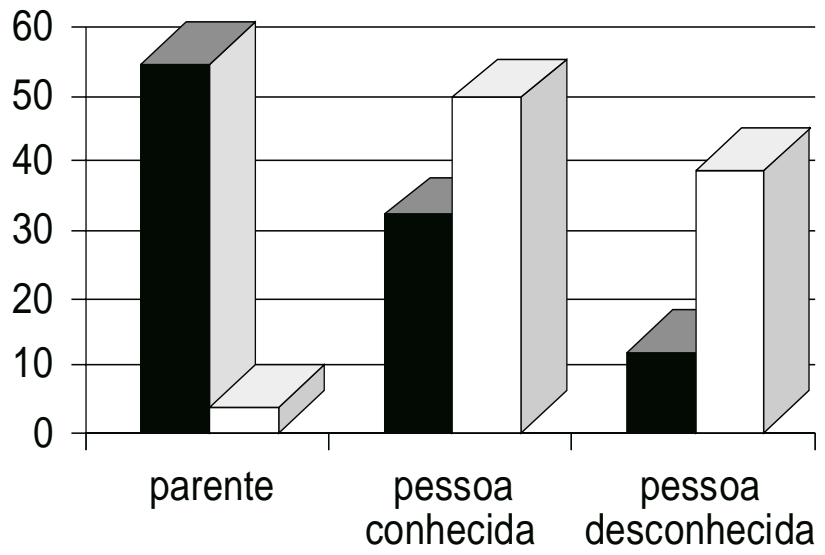

Ocorre que a roupa é muita e bastante suja. $66 \%$ das vítimas de violência em casa são mulheres. $74 \%$ delas estão na faixa de 18 a 50 anos de idade e em $70 \%$ são vítimas de agressões de parentes. As outras vítimas de agressões de parentes em casa são menores de 17 anos (28\%).

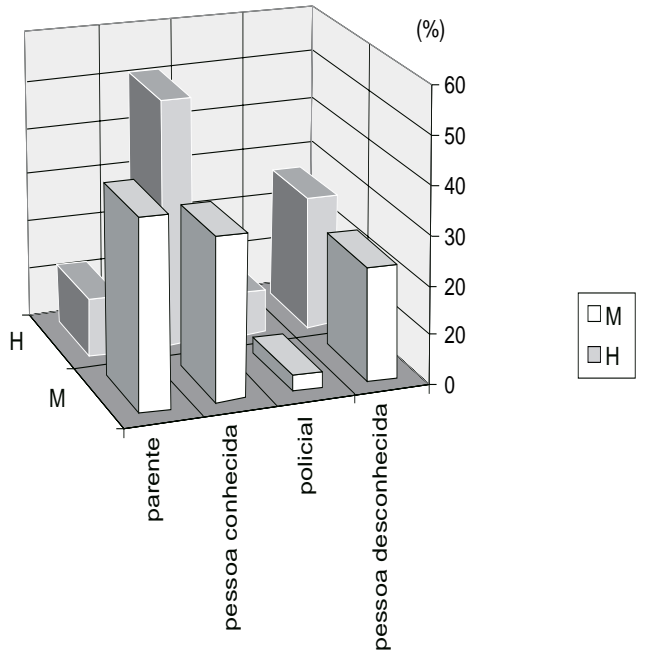

Conforme vemos, os dados sugerem um padrão de conflitos que raramente chega ao conhecimento da polícia por tratarem-se de conflitos senão domésticos, pelo menos que envolve pessoas conhecidas: o âmbito das relações privadas no Brasil expande-se além dos limites da vida familiar. Certamente no cômputo dos custos de se acionar o Estado está uma orienta-
4. Autor da agressão por local da última agressão - $M G$ (fonte: PNAD, 1988 e IBGE, 1990).
5. Autores das agressões por sexo - $M G$ (fonte: PNAD, 1988 e IBGE, 1990). 
6. Percentual dos motivos pelos quais as vítimas de furtos $e$ roubos não recorreram à polícia distribuídos pelos que tinham mais de 4 anos de estudo $e$ mais de 12 anos de estudo (fonte: PNAD, 1988 e IBGE, 1990). ção motivacional que demarca nitidamente uma linha divisória entre o nível formal e legal e o âmbito das relações pessoais.

Uma das hipóteses culturalistas correntes é que tais dados traduziriam uma espécie de "hobbesianismo social", marcada por uma enorme bolha de indiferença em relação a um Estado excessivamente legislador e regulatório (cf. Santos, 1993). Se, por um lado, temos um grau de participação político e social que marca uma relativa "cultura cívica" brasileira, por outro, esta não ultrapassa os limites de uma ínfima parcela da população. Contudo, os dados nos mostram que a ausência desta cultura cívica, se traduzidas naqueles que não buscam o amparo do Estado para a resolução de problemas, é tanto maior naqueles que são mais educados. Se separarmos apenas os que tinham poucos anos ou nenhum de estudo e compararmos com aqueles que tinham mais de doze anos de estudo, verificaremos que a atitude de descrédito puro e simples em relação à atuação da polícia se dá justamente entre as pessoas mais educadas.

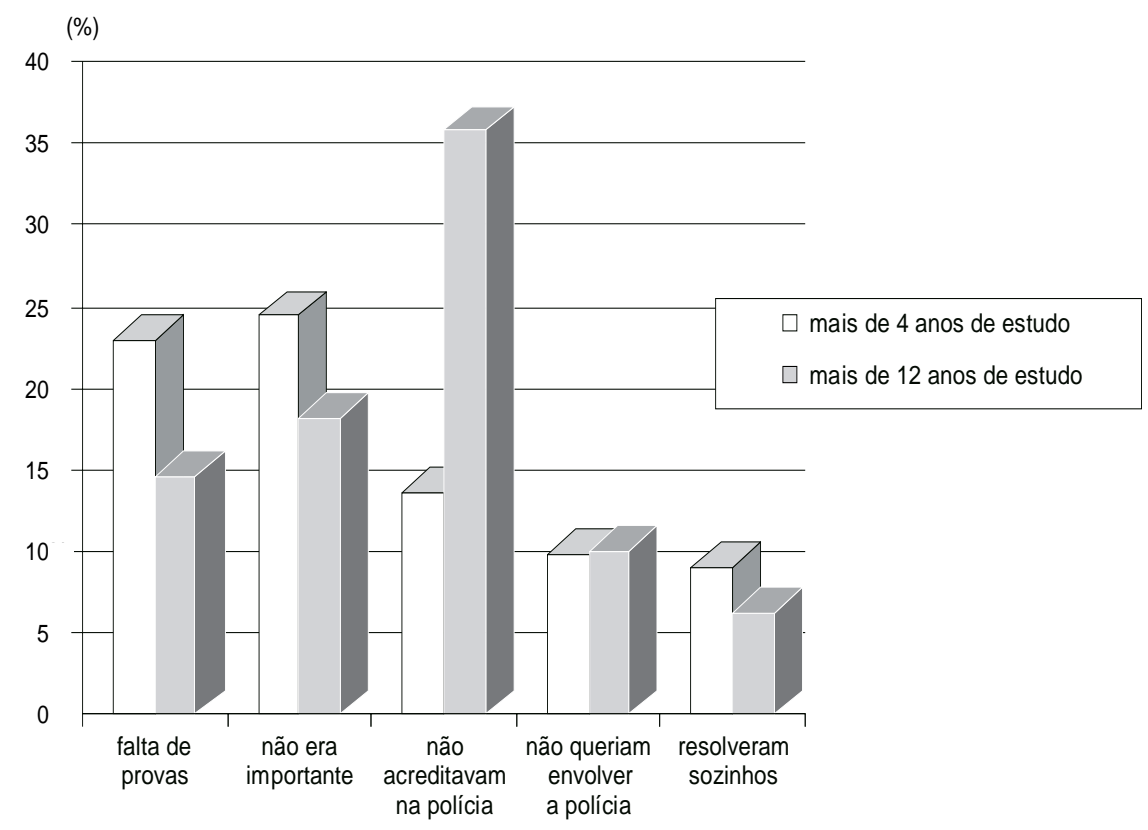

É interessante notarmos como a desconfiança e o descrédito daqueles que não acreditavam na polícia, e por isso não a procuraram, se dá entre as pessoas que são mais educadas numa proporção duas vezes maior do que entre aqueles que tinham menos de 4 anos de estudo. Seria de se esperar que essa cultura cívica (traduzida em algum grau na confiança nas instituições de mediação e dissuasão de conflitos) fosse maior entre as pessoas mais educadas, o que não ocorre.

Já temos alguns indícios do porquê as pessoas não acionam o Estado para a resolução de seus conflitos, resta-nos agora discutir quando elas recorrem à atuação policial. A PM de Minas Gerais registrou 892.710 ocorrências durante o ano de 1993 em todo estado. A maioria delas (27,5\%) 
referia-se a ocorrências contra a pessoa, logo seguido pelos crimes contra o patrimônio (22,9\%), acidentes de trânsito em cidades $(12,7 \%)$ e atividades assistenciais $(8,2 \%)^{4}$.

\begin{tabular}{|l|r|r|}
\hline \multicolumn{1}{|c|}{ Grupos de Ocorrência } & Ano de 1993 & $\%$ \\
\hline assistenciais & 64.690 & 8,2 \\
contra a pessoa & 215.632 & 27,5 \\
contra o patrimônio & 179.310 & 22, \\
contra costumes paz pública & 33.932 & 4,3 \\
contra incolumidade pública & 25.233 & 3,2 \\
referente a flora & 25.291 & 3,2 \\
referente a fauna & 14.592 & 1,9 \\
acidentes trânsito urbano & 99.738 & 12,7 \\
acidentes trânsito rodoviário & 11.230 & 1,4 \\
infrações de trânsito & 45.213 & 5,8 \\
defesa do meio-ambiente & 776 & 0,1 \\
referentes a drogas & 6.026 & 0,8 \\
referentes a incêndio & 8.427 & 1,1 \\
referentes à busca e salvamento & 7.799 & 1,0 \\
referentes a prevenção & 36.858 & 4,7 \\
solicitações & 9.727 & 1,2 \\
& & \\
TOTAL & 784.474 & 100,0 \\
\hline
\end{tabular}

As atividades em que a polícia é mais acionada tais como ocorrências contra a pessoa, patrimônio e trânsito são atividades policiais rotineiras. É notável, entretanto, o grande número de atividades assistenciais exercidas pela polícia em Minas Gerais, funcionando como uma via de acesso ao âmbito privado das populações, e que pode ter como consequiência a legitimação de sua ação em atividades que não são precípuas de sua natureza. A polícia é acionada com base numa percepção de senso comum do que pode ser considerado como um problema de ordem pública (cf. Espírito Santo, 1993). Tal percepção assenta-se em uma "pauta cultural", para utilizarmos um conceito de Schutz, 1964, a partir do qual identificam-se comportamentos e pessoas estranhas à sua rotina de relações estabelecidas cotidianamente e que requerem a atuação policial ${ }^{5}$. Esta pauta cognitiva de senso comum também permeia a atuação policial ostensiva, como nas atividades de investigação (cf. Bittner, 1975; Beato, 1993; Paixão, 1991). Nossa indicação é de que é este mecanismo que opera uma rígida separação entre público/privado, segundo o qual conflitos domésticos e de vizinhança não devem ser objetos de intervenção da esfera pública, ao passo que acontecimentos e pessoas "estranhas" são passivos da intervenção policial.

Podemos adotar como hipótese que esta lógica excludente e particularista consubstancia a prática de "justiçamentos", "polícias mineiras", e até mesmo a convivência promíscua estabelecida entre traficantes e uma
7. Registros de ocorrência policiais em Minas Gerais no ano de 1993 (fonte: Boletim Estatístico Operacional da Polícia Militar de MG. COPOM, 1994).

${ }^{4}$ Foram excluídos "referentes a diversos" por tratarem-se de procedimentos de rotina que não resultaram em ocorrências.

5 Para Schutz (1964, p.100) esta discussão está referenciada ao problema do "estrangeiro" que, justamente por não compartilhar de um sistema de conhecimento de um grupo, termina por gerar um sentimento de desconfiança em relação a ele: "para cada um, somente as formas de vida de seus pais e avós passam a ser elementos da sua própria. Os sepulcros e as recordações não podem ser transferidos nem conquistados". Este sentimento de "estranheza" é que estava na origem do tratamento da questão dos emigrantes na República Velha como um problema de polícia . 
${ }^{6}$ É interessante como a execução sumária de um bandido frente às câmaras de televisão, ocorrida recentemente no Rio de Janeiro, gerou um imenso movimento de apoio à atitude do policial. A perplexidade ficou por conta do fato ocorrer publicamente, com a mídia eletrônica registrando inadvertidamente o episódio e não o fato em si. comunidade que prefere a ordem à margem da lei do que a desordem sob um Estado ineficiente. Conforme vimos, os elementos que compõem essa pauta nem sempre orientam-se por categorias legais e canais institucionais de resolução de conflitos, mas por uma dupla lógica que termina por contaminar a atuação policial sob a demanda de que se "faça a justiça" apesar da lei. Se temos um quadro no qual se admite a violência, o conflito e a arbitrariedade no âmbito das relações privadas e familiares, a ocorrência da desordem no âmbito público geram demandas que admitem a atuação discricionária e arbitrária da polícia. $\mathrm{O}$ apoio a formas truculentas de ação da polícia é um traço recorrente nas intervenções espetaculares do poder público no combate à violência. Na verdade, tais ações dirigem-se mais à opinião pública do que a resultados concretos e palpáveis no combate à criminalidade.

Preliminarmente podemos concluir que não estamos propriamente diante de um estado de natureza, mas de uma ordem estruturada a partir de fatores culturais que dissociam a esfera pública da privada, traduzida no célebre dilema brasileiro da igualdade (universalidade e legalidade no plano político institucional) e da desigualdade (hierarquização e regras truculentas de convivência no plano social). Esta disjunção não é da mesma natureza daquela existente em determinados bolsões em que a lógica familística e privada é substituída por normas de convivência implementadas por grupos para-estatais em que, aí sim, vigora a lei do mais forte. Os valores conservadores e tradicionais expressos nessa lógica cultural delimitarão o âmbito de atuação do sistema de justiça criminal e, especialmente, na atuação da polícia através de demandas sobre o sistema que deve articular estes dois planos: de um lado, a atividade policial se dá num contexto crescente de controle da sua atuação pelas instituições democráticas; de outro, sua eficiência é julgada pelo mesmo mecanismo que opera a disjunção público/privado a partir de lógicas distintas. A julgar pelos dados expostos acima e pelas últimas pesquisas a respeito das expectativas em relação à atuação do Estado no combate à criminalidade, talvez fosse o caso de introduzirmos no debate atual a medida em que a população demanda uma atuação arbitrária do Estado no combate ao problema da violência ${ }^{6}$.

\section{Conclusão}

A discussão anterior nos conduz a uma linha de investigação de organizações policiais bastante distinta da perspectiva dominante de análise sociológica dos sistemas de justiça criminal. Esta postula seu papel instrumental na articulação da legalidade e da ordem social - no plano das interações sociais rotineiras. A análise de um dos segmentos do sistema - a polícia - oferece ilustração da adesão macrossociológica à perspectiva instrumental. A tradição normativa sempre demonstrou predileção pelos mecanismos naturais, emergentes de controle social, dos quais resulta a explicação da conformidade como resultado de processos bem sucedidos de 
socialização, pelos quais as normas de cultura institucionalizada são internalizadas no sistema de personalidade do ator social. Logo, o papel da organização policial é rigorosamente residual e referido à garantia, face ao fracasso dos "mecanismos naturais" de controle, da implantação coercitiva das regras obrigatórias da sociedade. O consenso, mais do que a coerção, explica a integração normativa da sociedade moderna: "a sociedade de massa não é a sociedade mais pacífica ou 'ordeira' que já existiu, mas é a mais consensual. A manutenção da paz pública através da apatia e da coerção numa estrutura de interação extremamente descontínua é uma coisa bem diferente de sua manutenção através do consenso numa estrutura de interação mais contínua entre o centro e a periferia" (Shils, 1962). Da mesma forma, os marxistas definem o sistema de justiça criminal como aparelho repressivo do Estado - uma "arma organizacional" de garantia coercitiva da estabilidade do sistema de dominação de classe (cf. Balôus, 1985; Baskin, 1991).

A lógica instrumental supõe uma articulação rígida entre estrutura e função nas operações práticas do sistema de justiça criminal (Hagan, 1989). Este, para os funcionalistas, ao implementar a legalidade, expressa e reproduz o consenso normativo que torna a sociedade possível. O teste empírico dessa suposição reside na proposição que associa decisões judiciárias e variáveis puramente legais. Para os marxistas, o sistema de justiça criminal é um instrumento coercitivo de preservação da dominação de classe e seu teste empírico depende da evidência do efeito de variáveis extra-legais sobre as decisões do sistema: "em outras palavras, os modelos marxistas e durkheimeanos discordam quanto aos fatores que supostamente influenciam as decisões legais, mas concordam quanto à estruturação de tais decisões, de tal forma que um ou outro conjunto de fatores possa exercer uma influência profunda" (Hagan, 1989).

Contudo, nossa discussão sugere a possibilidade de manutenção de sistemas de ordem sem referência estatal. Mecanismos de controle operam em vários níveis, nos quais a estrutura legal convive ao lado de regras organizacionais, das normas advindas de forças sociais, dos contratos controlados pelas partes interessadas e da dimensão ético-pessoal (cf. Ellickson, 1991). Qual desses níveis será evocado é resultado de contextos específicos e matéria de deliberação empírica por parte dos atores envolvidos numa situação de conflito. Dito em outras palavras, trata-se de um cálculo racional em que as partes envolvidas ponderam os custos de uma decisão de envolver o nível formal e legal quando podem recorrer a outras esferas privadas, paroquiais e locais de resolução de conflitos. Na avaliação desses custos, elementos de ordem cultural parecem emergir na implementação das regras legais e normas sociais em contextos específicos de ação. Isto coloca-nos diante de alguns paradoxos cruciais do ponto de vista da análise de processos de controle social: o primeiro deles tem a ver com a emergência de sistemas informais, nativos de controle como resposta à percepção de populações das instituições do sistema de justiça criminal como preconceituoso, enviesado e arbitrário na provisão 
de justiça e paz (cf. Santos, 1982); outro refere-se à desconfiança, quando não ao medo das populações, especialmente de baixa renda, em relação a certos atributos do trabalho policial. Este ponto tem sido excessivamente explorado na vasta "literatura de acusação" produzida pela sociologia do crime no Brasil que passa ao largo de uma inquietante descoberta empírica: o arbítrio e a violência podem ser resposta do policial a demandas da população especialmente de baixa renda (cf. Paixão, 1988).

Neste artigo exploramos uma área temática em geral negligenciada pela sociologia brasileira: a permeabilidade das organizações do sistema de justiça criminal ao meio-ambiente. Em que medida a lógica dual público/ privado exposta anteriormente não termina por contaminar a atuação da organização policial, introduzindo um elemento de ambigüidade explorado vastamente na literatura. Muito do que é tomado como indicador de ineficiência do trabalho policial é resultado desta ambigüidade: as pessoas não recorrem à polícia apenas por temor ou descrença, mas por se recusarem a admitir a interferência do Estado em sua vida privada. Nesse sentido, as reações dos cidadãos brasileiros não seriam muito diferentes daquelas observadas em democracias consolidadas. Evidentemente esta afirmação deve ser qualificada, dada a escassez de pesquisa comparativa.

O diagnóstico do problema da violência urbana no Brasil - ainda que precário - aponta para enormes dificuldades, no plano das políticas públicas, na realização de objetivo portentoso: desmontar a máquina que monta o que Fábio W. Reis já descreveu como o "pior dos mundos possíveis" (cf. Reis, 1988). A polícia e a justiça afetam minimamente as taxas de criminalidade, tampouco se orientam pelas regras que, idealmente, conteriam o poder social e político na produção de ordem. Por outro lado, lacunas cognitivas tendem a ser compensadas pela adesão a alguma perspectiva leiga sobre as causas, conseqüências e terapias adequadas de correção do problema - da qual resulta a substituição da análise fina pela celebração de algum mito socialmente cultuado - o pobre criminoso, o crime como denúncia da opressão, o criminoso patológico... Daí que as recomendações de políticas de controle do crime derivadas da discussão leiga ou ilustrada são contraditórias, recorrentes e banais: políticas de renda, emprego e redução da miséria convivem com propostas de aumento do número de policiais, promotores, varas criminais e do tamanho e gravidade das penas - já houve quem sugerisse ao Ministério da Justiça a execução de criminosos hediondos no intervalo de jogos de futebol.

Enquanto isso, bandidos e quadrilhas de "vingadores" e "justiceiros" constroem um sistema de justiça privado no qual a polícia não opera ou tornase fator adicional de desordem. Não há como ignorar os custos elevadíssimos correspondentes ao modelo de ordem implementado pelo crime organizado na periferia social (cf. Zaluar, 1985; Paixão, 1991). O problema público da criminalidade violenta no Brasil articula dois dilemas cruciais do ponto de vista da institucionalização das liberdades civis entre nós: aos dilemas "antigos" de domesticação da polícia e de abertura do judiciário às classes populares 
agregam-se os problemas "modernos" postos pela privatização da segurança (cf. Paixão, 1991). A indignação moral somada à perplexidade diante da brutalidade da polícia e da solidaridade das populações a este tipo de ação, das incertezas da punição de predadores e da ineficiência agregada do sistema de justiça criminal não deve inibir a consideração realista do Estado e suas organizações como "intrumentalidade institucional" de provisão de justiça e paz.

Recebido para publicação em janeiro/1997

PAIXÃO, Antônio Luiz \& BEATO F., Claudio C. Crime, victims and policemen. Tempo Social; Rev. Sociol. USP, S. Paulo, 9(1): 233-248, May 1997.

ABSTRACT: The authors discuss a victimization survey by PNAD 88, to analyse the relationship between police and society and the motivation that take people to call the police. In contrast to a "culturalist" explanation, we suggest that there is a racional motivation that carry people to call the police to solve conflicts.

\section{REFERÊNCIASBIBLIOGRÁFICAS}

Almond, G. \& Verba, S. (1965) The civic culture. Boston, Little Brown.

Arendt, Hanna. (1985) Da violência. Brasília, UnB.

BASKIn, D. (1991) Community mediation and the public/private problem. Social Justice, 15(1).

Beato F., Claudio C. (1992) Suicídio ou homicídio: a definição de um fato. Análise e Conjuntura, Fundação João Pinheiro, 7(2).

BITTNER, E. (1975) The functions of the police in modern society. New York, Jason Aronson.

Coelho, E.C. (1988) A criminalidade urbana violenta. Dados, 31(2):145183.

ELLICKSON, R.C. (1991) Order without law: how neighbors settle disputes. Harvard University Press.

ENGELs, F. (1968) The condition of the working class in England. Stanford, Stanford University Press.

Hagan, J. (1989) Structural criminology. New Brunswinck, Rutgers University Press.

IBGE. (1990) Participação político-social. Vol. 1, Justiça e Vitimização. Rio 
de Janeiro, FIBGE.

Manning P. (1977) Police work. Cambridge, MIT Press.

Monet, J. (1985) Une administration face à son avenir: police et sciences sociales. Sociologie du Travail, 4: 370-390.

OfFe, C. (1987) Democracy against the Welfare State? Political Theory, 15(4): 501-537.

PAIXÃo, A. L. (1988) Crime, controle social e consolidação da cidadania. In: ReIs, F. \& O’Donnell, G. (eds.). A democracia no Brasil. São Paulo, Vértice.p. 168-199.

. (1991) Segurança privada, direitos humanos e democracia: notas preliminares sobre novos dilemas políticos. Novos Estudos CEBRAP, 31: 131-141.

REIS, F. W. (1988) Consolidação democrática e construção do Estado. In: \& O’Donnel, G. (eds.). A democracia no Brasil. São Paulo, Vértice.

SANTOS, Boaventura de Souza. (1982). Law and community: the changing nature of State power in late capitalism. In: ABEL, R. (org). The politics of informal justice. The American experience. Vol. 1. New York, Academic Press.

Santos, W. (1993) As razões da desordem. Rio de Janeiro, Rocco.

Silver, A. (1967). The demand for order in civil society.In: BorduA, D. (ed.). The police. New York, Wiley.

Skolnick, J. (1966) Justice without trial, New York. In: Wiley \& BAYLEY, D. (1986) The new blue line, New York, Free Press.

Tittle, C., et alii. (1978) The myth of social class and criminality. American Sociological Review, 43: 643-656.

Zaluar, A. (1984). A máquina e a revolta. São Paulo. Brasiliense. 